\title{
Goals of Referring Acts
}

\author{
Amichai Kronfeld \\ AI Center \\ and \\ Center for the Study of Language and Information \\ SRI International \\ 333 Ravenswood Avenue \\ Menlo Park, CA 94025
}

October 15, 1986

\section{Motivation}

A pragmatic theory of reference is a theory that specifies and explains the human competence to use referring expressions in order to achieve certain goals. Since the relation between referring expressions and speaker's goals is what needs explaining, it is natural to consider referring as planned action $[1,4,5]$. This, in turn, requires showing how the use of referring expressions is systematically related to changes in the hearer's mental state. For that purpose, we need to know the speaker's goals concerning the hearer's mental state, and therefore, a pragmatic theory of referring must first of all specify and describe the goals that typically motivate the use of referring expressions. It is with such goals that this paper is concerned.

The view that the referring act is a planned effort to achieve certain goals through linguistic means simply follows from the fact that referring is a speech act: all speech acts are attempts to achieve certain goals through linguistic means. However, referring acts (and in general, propositional acts) are significantly different from illocutionary acts such as asserting and requesting:

Literal goals. In performing one and the same speech act, a speaker may have many distinct goals. For example, by saying "The house's on fire!", a speaker may intend to inform the hearer that the house is on fire, scare the hearer half to death, as well as make the hearer leave. Only the first goal, however, is what I call a literal one ${ }^{1}$. Literal goals are the goals of Gricean communication intentions, i.e., they are intended to be achieved

\footnotetext{
${ }^{1}$ The term is taken from Kasher [9], where literal purposes are introduced. My use of the term, though, is slightly different.
} 
partly through the recognition of the intention to achieve them. Thanks to Austin, Grice, Searle and others, we have a fairly clear notion of what the literal goals of illocutionary acts are. For example, the literal goal of a promise is to let the hearer know that the speaker places himself under an obligation to do something. But it is not clear at all what the literal goal of a referring act is.

Conditions of satisfaction. Illocutionary acts have propositional content, but referring acts do not. The propositional content of an illocutionary act determines what Searle [13] calls its conditions of satisfaction: a request that the door be opened is satisfied iff someone opens the door, and an assertion that the door is closed is satisfied (true) iff the door is indeed closed. But since a referring act lacks propositional content, it is not clear what its conditions of satisfaction are ${ }^{2}$.

Syntax and Semantics. In (direct) illocutionary acts, we have a fairly precise correlation between syntax and semantics on the one hand, and illocutionary point on the other. Assertions and commands, for example, have their syntactic counterparts in indicative and imperative sentences, and illocutionary points are represented by performative verbs. But while a serious utterance of an imperative sentence is almost always taken as a directive type of speech act, the serious utterance of a noun phrase - even a definite noun phrase is not necessarily an act of referring. Similarly, one can promise, say, to pay one's debt by stating: "I hereby promise to pay my debt," but merely uttering "I hereby refer to a friend of mine" is hardly satisfactory. Thus, the semantic and syntactic clues that enable the hearer to recognize an illocutionary act do not help much as far as referring is concerned.

Compositionality. The major difference between propositional acts and illocutionary ones is that the latter are constructed out of the former and not vice versa. Referring and predicating are related to illocutionary acts as the form and meaning of NP's and VP's are related to the form and meaning of a full sentence. In pragmatics, as in syntax and semantics, it must be shown how the whole is a function of its parts. One way of stating the problem is in terms of pragmatic presuppositions. The pragmatic presuppositions of a speech act can roughly be described as the class of propositions that is characteristically associated with felicitous performances of that speech act. The truth of these propositions is mutually believed to be taken for granted by the participants [8]. Now, it would be difficult to see how such a class of pragmatic presuppositions is generated, unless the pragmatic presuppositions associated with illocutionary acts are to a large extent a function of the pragmatic presuppositions associated with parts of the illocutionary acts, namely, propositional acts. For example, a pragmatic presupposition of the command "Show me the letter!" is that it is mutually believed that a certain letter exists and both speaker and hearer know which one it is. This pragmatic presupposition is generated through other

\footnotetext{
${ }^{2}$ Note that specifying the conditions of satisfaction of a referring act is not the same as specifying its literal goal. The literal goal of a speech act and its conditions of satisfaction are usually distinct: If I tell you that I want the door closed and you understand me, the literal goal of my request is achieved. But it is still up to you whether or not to satisfy my request.
} 
presuppositions that are associated with the propositional act of referring: for example, that it is mutually believed that the use of the definite article in this case signals an anaphoric link with a referring expression mentioned earlier.

To sum up, we have four problems with respect to referring acts which seem harder to resolve than their corresponding problems in a theory of illocutionary acts:

1. What is the literal goal of a referring act?

2. What are its conditions of satisfaction?

3. When is an NP a referring expression, and what role does its meaning play in the referring act?

4. How does referring contribute to the success of illocutionary acts?

In this paper I concentrate on the first two questions. I argue that in order to answer them, we must develop a pragmatic (as opposed to an epistemological) concept of referent identification. I then sketch a model of referring that is capable of representing such a concept.

\section{$2 \quad$ Literal and Identification Goals}

The literal goal of referring. The literal goals of all speech acts are to affect the hearer's propositional attitudes in a particular way. Intuitively, the point of referring is to let the hearer know what is being talked about. The literal goal of the referring act must be, therefore, to make the hearer believe that it is mutually believed by all participants that a noun phrase is being used as a referring expression, and that "identification" of a particular object is required.

Rules for identification. What counts as "proper identification" changes from discourse to discourse. For example, in "Replace this 300-ohm-resistor," the hearer is asked to "identify" the referent in the sense of locating it in his visual field. But in "Tell me what other plays were written by the author of Hamlet," visual identification is clearly not required, although the hearer is still expected to identify the author of Hamlet in another way. If the point of the referring act is the establishment of mutual agreement as to which object is being talked about, then a necessary condition for successful referring is that the hearer understand the ground rules for establishing such mutual agreement. These ground rules, which change from discourse to discourse, should be arrived at by the analysis of what we call the pragmatic notion of referent identification.

Identification goals. Understanding the ground rules for referent identification is not the same as following these rules. While the literal goal of a referring act is that the hearer recognize the speaker's intentions that the hearer identify an object in a particular way, the condition of satisfaction of the referring act is that the hearer actually identify the referent 
as required. Under typical circumstances, understanding the utterance "Replace the 300ohm resistor" entails understanding that visual identification of the resistor is required. Another question entirely is whether actual identification eventually takes place. Let us call the goal that actual identification takes place as required the identification goal.

To sum up, we have defined the literal goal and the conditions of satisfaction of referring in terms of what the hearer is supposed to believe and do respectively. The literal goal is divided into two parts: first, making the hearer believe that identification of a particular object is required, and second, making him realize what kind of identification is appropriate. The referring act is satisfied when the hearer successfully follows the rules for correct identification.

\section{A Model of Referent Identification}

How can literal and identification goals be represented in a model of referring? We need two concepts, individuating sets and identification constraints.

Individuating sets. Any model of referring must include representations of objects in the agent's model of the world. Such representations must be grouped into individuating sets. An individuating set $S$ of an agent $A$ is a maximal set of terms, all believed by $A$ to denote the same object. The terms that constitute an individuating set can be either perceptual or descriptive. Perceptual terms are obtained by perceptual acts (e.g. looking at an object), while descriptive terms are obtained through the use of referring expressions in discourse ${ }^{3}$.

A speaker intends to invoke or activate an individuating set when he intends a particular individuating set to be used in the interpretation of the current utterance. The notion of an individuating set being invoked or activated is closely related to the idea of an item being in focus during a discourse segment $[6,7]$. One can imagine a dynamic stack of active individuating sets representing the objects under discussion.

Do we really need individuating sets? The answer is yes, for two important reasons. First, individuating sets provide elegant solutions for several problems that are raised by the Referential/Attributive distinction $[10,11,12]$. Second, as we have seen, a major problem for a referring model is specifying the conditions under which a hearer can be said to have identified the intended referent. Some authors have required that for identification to take place, the agent must possess a standard name or a rigid designator that denotes the referent. But very few objects are endowed with standard names, and it can be easily shown that a rigid designator is neither sufficient nor necessary for successful referent identification [12]. Moreover, requiring agents to know standard names or rigid designators for individuals that they refer to makes some undesirably strong predictions about what a speaker must know in order to refer to something [2]. Using individuating sets we can solve these problems.

\footnotetext{
${ }^{3}$ For a more detailed discussion of individuating sets and their terms see $[3,12]$.
} 
Identification constraints As noted earlier, "identification" should be interpreted pragmatically. Referent identification does not mean knowing who (or what) the referent is, but rather knowing who or what is being talked about. In general, the requirements for referent identification can be characterized in terms of constraints that the speaker places on the activated individuating set. I call these constraints identification constraints.

Let $S$ be the activated individuating set. The following examples illustrate different identification constraints on $S$ :

Example 1 Take this chair to my office.

In Example 1, the hearer should "identify" the chair in the sense of locating it in his visual field. We can express this requirement as a constraint on $S$ that it contain a new perceptual term.

Example 2 Do you remember the brown desk I used to have in my office?

In Example 2, the identification constraint is that the $S$ should contain an old perceptual term, i.e. "identification" consists of connecting a definite description with an image in memory.

Example 3 A friend of mine has just won $\$ 10,000$ in a sweepstakes, but the lucky bastard will probably gamble it all away.

Identification constraint: that $S$ activated by the description "The lucky bastard" be augmented to include a term that has already been introduced into the discourse. "Identification" here is simply making an anaphoric connection.

Example 4 My sister has just got married. The lucky man met her only three weeks ago.

Identification constraint: the $S$ should contain the description "the husband of the speaker's sister". Note the difference between this case and Example 3: the description "my sister's husband" was never mentioned, and had to be deduced by the hearer. The deduction, of course, is a necessary condition for successful identification.

Example 5 The man whose fingerprints these are, whoever he is, must be insane.

Assume that the context of Example 5 is as follows: the speaker is investigating the horrible murder of Smith, and he has just found clear fingerprints on what he believes to be the murder weapon. The speaker, of course, wishes to assert that whoever murdered poor Smith in such a terrible way must be insane. Hence the identification constraint is that the $S$ should contain the description "Smith's murderer". This example illustrates why we insist that identification as the goal of the referring act is a pragmatic, rather than an epistemological concept. Neither speaker, nor hearer in this case have any idea who murdered Smith, and thus, they cannot identify him in any epistemological sense of the term. But from a pragmatic point of view, there is a clear dichotomy: if the hearer makes the connection between "The man whose fingerprints these are," and "Smith's murderer," he has identified who the speaker is talking about. Otherwise, he has not. 
Example 6 I met an old friend of mine yesterday.

This is the case of the null set of identification constraints. $S$ contains a single term, and this is sufficient for pragmatic identification.

These examples show that the requirements for referent identification can be very diverse indeed. They all can be represented, however, as constraints on relations among individuating sets.

The referring act. Armed with the concepts of individuating sets and identification constraints, we can characterize the act of referring as an act of conveying an ordered pair: an individuating set (which becomes the active one), and a set of identification constraints. The literal goal of the referring act is that it is mutually known by all participants which individuating set is active, and what the identification constraints are. The referring act is satisfied if the hearer is able to manipulate the active individuating set in such a way that all identification constraints are met.

\section{Acknowledgements}

This research was supported by the National Science Foundation under grant DCR-8407238. I am grateful to Doug Appelt for comments on earlier drafts, and for lots of stimulating discussions on the problem of constructing a computational model of referring.

\section{References}

[1] Douglas E. Appelt. Planning English Sentences. Cambridge University Press, Cambridge, England, 1985.

[2] Douglas E. Appelt. Some pragmatic issues in the planning of definite and indefinite noun phrases. In Proceedings of the 23rd Annual Meeting, Association for Computational Linguistics, 1985.

[3] Douglas E. Appelt. Toward a plan-based theory of referring actions. In Proceedings of the 3rd International Workshop on Language Generation, Nijmegen, The Netherlands, August 19-23 1986.

[4] Philip R. Cohen. On Knowning What to Say: Planning Speech Acts. PhD thesis, University of Toronto, 1978.

[5] Philip R. Cohen and C. Raymond Perrault. Elements of a plan-based theory of speech acts. Cognitive Science, 3:117-212, 1979.

[6] Barbara J. Grosz. Focusing and description in natural language dialogues. In A. Joshi, I. Sag, and B. Webber, editors, Elements of Discourse Understanding, pages 85-105, Cambridge University Press, Cambridge, England, 1980. 
[7] Barbara J. Grosz and Candace L. Sidner. Discourse structure and the proper treatment of interruptions. In Proceedings of the Ninth International Joint Conference on Artificial Intelligence, pages 832-839, 1985.

[8] Asa Kasher. Philosphy and discourse analysis. In Handbook of Discourse Analysis, Vol. 1, chapter 9, pages 231-248, Academic Press, Inc., 1985.

[9] Asa Kasher. What is a theory of use. Journal of Pragmaics, 1:105-120, 1977.

[10] Amichai Kronfeld. The Referential Attributive Distinction and the ConceptualDescriptive Theory of Reference. $\mathrm{PhD}$ thesis, University of California, Berkeley, 1981.

[11] Amichai Kronfeld. Reference and Denotation: The Descriptive Model. Technical Note 368, SRI International Artificial Intelligence Center, 1985.

[12] Amichai Kronfeld. Donnellan's distinction and a computational model of reference. In Proceedings of the 24th Annual Meeting, Association for Computational Linguistics, 1986.

[13] John Searle. Intentionality: An Essay in the Philosophy of Mind. Cambridge University Press, Cambridge, England, 1983. 